\title{
Microfabricated Implantable Pressure Sensor for Flow Measurement
}

\author{
Sheng Liu, Reginald Farrow and Gordon Thomas \\ Physics Department, New Jersey Institute of Technology, Newark, NJ \\ USA
}

\section{Introduction}

Gas and liquid pressure and flow are required to be measured and controlled in many applications, such as biomedical system, environmental monitoring and industrial control. Capacitive pressure and flow sensors have been developed and the detailed capacitive pressure sensors have been reviewed and most capacitive sensors use silicon, glass, silicon nitride membrane as sensing plate (Puers, 1993; Baxter, 1997). But in some applications like implanted medical devices, poison gases and high temperature places, the flow is not easy to be recorded. People have developed ways to measure flow and pressure remotely (Akar, 2001; Ong, 2001; Grimes, 2000). The pressure and flow sensors use capacitor as sensing part (Akar, 2001; Oosterbroek, 1999). Combined with the inductor, they are designed as LC resonant circuit. And the LC circuit resonant frequency can be measured by external wireless circuit. From measuring the resonant frequency change, the flow and pressure can be shown. This paper presents a new designed RF wireless capacitive flow and pressure sensor. The design has a parallel capacitor and thin film spiral square inductor as resonant circuit. The capacitor is sensing the pressure change. The inductor is fabricated with the capacitor on wafer using MEMS technique. Because the sensors are used to measure $\mathrm{cmH} 2 \mathrm{O}$ pressure, the capacitor has to be very sensitive. One ultra low stress Silicon Nitride was used as the sensing membrane.

\section{Sensor design and fabrication}

In this section, sensor design and fabrication methods are going to be talked. For flow sensor design, the flow rate and sensor sensitivity have to be concerned first. A RF wireless pressure sensor has been developed. The design has a parallel capacitor and thin film spiral square inductor as resonant circuit. The capacitor is sensing the pressure change. The inductor is fabricated with the capacitor on wafer using MEMS technique.

\subsection{Silicon nitride membrane deflection}

Flow and pressure sensors use capacitor as sensing part. The capacitor has two parallel plates, one is fixed, one is deflected under pressure. However, the residual stress in the sensing membrane plays an important role. It will be talked first. In all cases, the deflection of membrane under pressure is described by in equation (1) (Vlassak, 1992; Pan, 1990): 


$$
P=\frac{B_{1} t \sigma_{0}}{a^{2}} \delta+\frac{B_{2} f(v) t E}{a^{4}(1-v)} \delta^{3}
$$

where $\mathrm{P}$ is the pressure, $\delta$ is the deflection of membrane under pressure, $\mathrm{t}$ is the thickness of membrane, $a$ is the radius or half length of the membrane, E is Young's Modulus, $v$ is Poisson Ratio, $\sigma_{0}$ is the initial or residual stress, $B_{1}, B_{2}$ are dimensionless constants, $f(v)$ is function geometry and model depended. These parameters are listed in Table. 1.

\begin{tabular}{|c|c|}
\hline Parameter & Value \\
\hline Pressure range $\left(\mathrm{cmH}_{2} \mathrm{O}\right)$ & $0-45$ \\
\hline Thickness of LPCVD SiN ${ }_{x}$ membrane (nm) & 500 \\
\hline Half width of LPCVD SiN ${ }_{x}$ membrane (mm) & 0.686 \\
\hline Young's Modulus of LPCVD SiN ${ }_{x}$ membrane (Gpa) & 90 \\
\hline Poison's ratio of LPCVD $\mathrm{SiN}_{\mathrm{x}}$ membrane & 0.25 \\
\hline Dimensionless constant $\mathrm{B}_{1}$ & 3.23 (Pan, 1990) \\
\hline Dimensionless constant $\mathrm{B}_{2}$ & 1.37 (Pan, 1990) \\
\hline Geometry and model dependant function & $1.26-0.36 \mathrm{v}$ (Pan, \\
\hline \multicolumn{2}{|l|}{ 1990) } \\
\hline Inductance $(\mathrm{nH})$ & 14 \\
\hline Capacitor plates spacing (nm) & 500 \\
\hline Resonant frequency as $\mathrm{P}=0(\mathrm{GHz})$ & 1.37 \\
\hline Residual Stress (GPa) & 139 \\
\hline
\end{tabular}

Table 1. LPCVD SiNx membrane characteristics and used parameters for initial stress computation, summarized characteristics and expected performance parameters of pressure sensor.

For square membranes, the magnitude of the deflection, $z$, as a function of position on the membrane, $x$ and $y$, can be described by (Pan, 1990).

$$
z=\delta \cos \left(\frac{\pi x}{2 a}\right) \cos \left(\frac{\pi y}{2 a}\right)
$$

For the circular membrane as a hemispherical cap as follows (Pan, 1990):

$$
z=\delta-R+\sqrt{R^{2}-r^{2}}
$$

where $\mathrm{R}$ is radius curvature of the deflected membrane given in Equation (3), $\mathrm{r}$ is the distance from the membrane center, and

$$
R=\frac{a^{2}+\delta^{2}}{2 \delta}
$$

The membrane sensitivity, $S$, is defined by the derivative of displacement with respect to pressure:

$$
S=\frac{d \delta}{d P}
$$


The full form of $S$ is complicated, but in the region of deflection less than 5 microns shown in Figure 1, the second term of displacement $\delta$ in Equation 1 is negligible and $S$ is given just by the first term. Therefore,

$$
S=\frac{a^{2}}{B_{1} t \sigma_{0}}
$$

The main result here is that $S$ decreases as the inverse of the residual stress, $\sigma_{0}$. Three values of $\sigma_{0}$ are shown in Figure 1, where the inverse of the linear slopes is the membrane sensitivity.

The other result illustrated in Fig. 1 is that, if the residual stress were to approach zero, the sensitivity would be given by the inverse slope of the second term in Equation 1 that is cubic in $\delta$. In this case the sensitivity would be extremely high at low displacements tending toward infinity as the displacement approaches zero in the approximation of Equation (1).

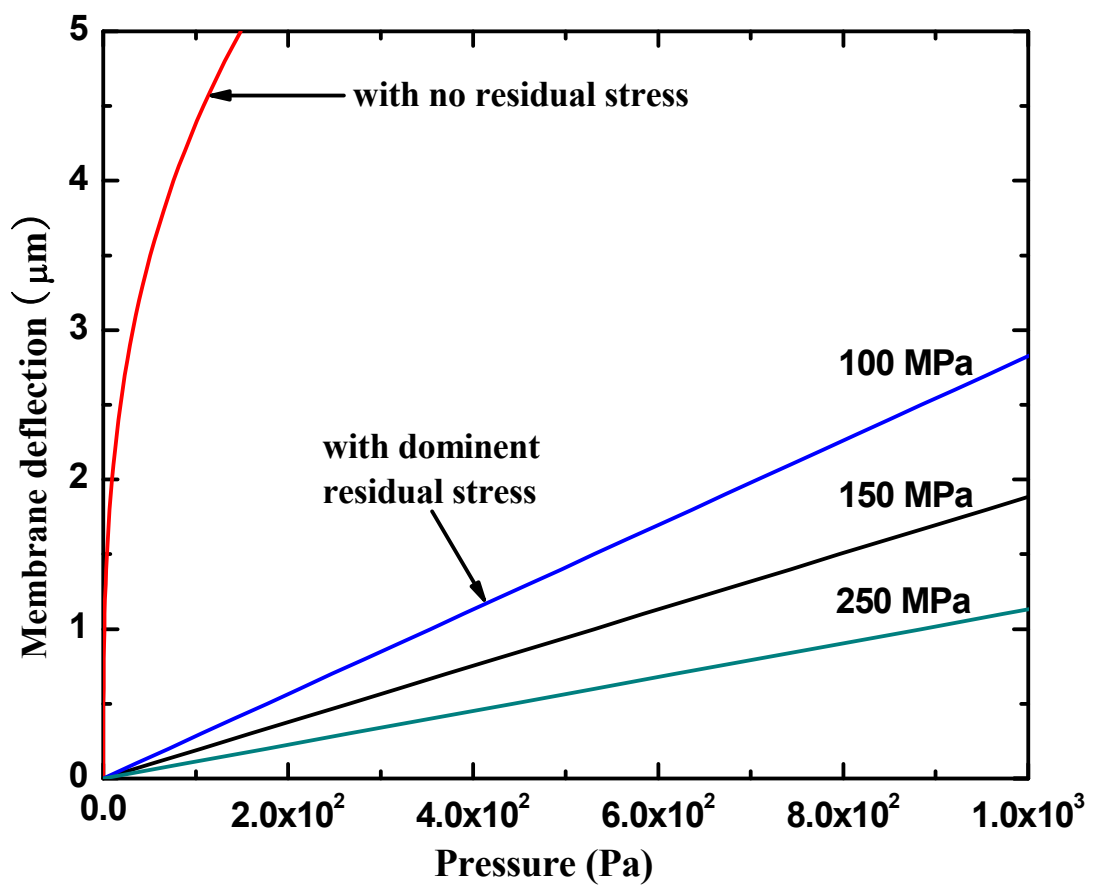

Fig. 1. Computed results for the pressure related to two terms with and without residual stress of Equation 1 as a function of membrane deflection. The lower lines are proportional to the residual stress and are shown for 3 values of it. For higher residual stress, the sensitivity $d \delta / d P$ is smaller, as shown. The membrane sensitivity is proportional to the slope. With achievable value of residual stress, the first term dominates below about 5 microns, where increasing residual stress produces lower sensitivity. If the residual stress were negligible, the sensitivity would be determined by the slope of the second term and would be extremely high. 
At small pressures according to Equation 6, the sensitivity is increased as the membrane dimension increases and as the thickness decreases. The computed results were plotted in Figure 2 and Figure 3.

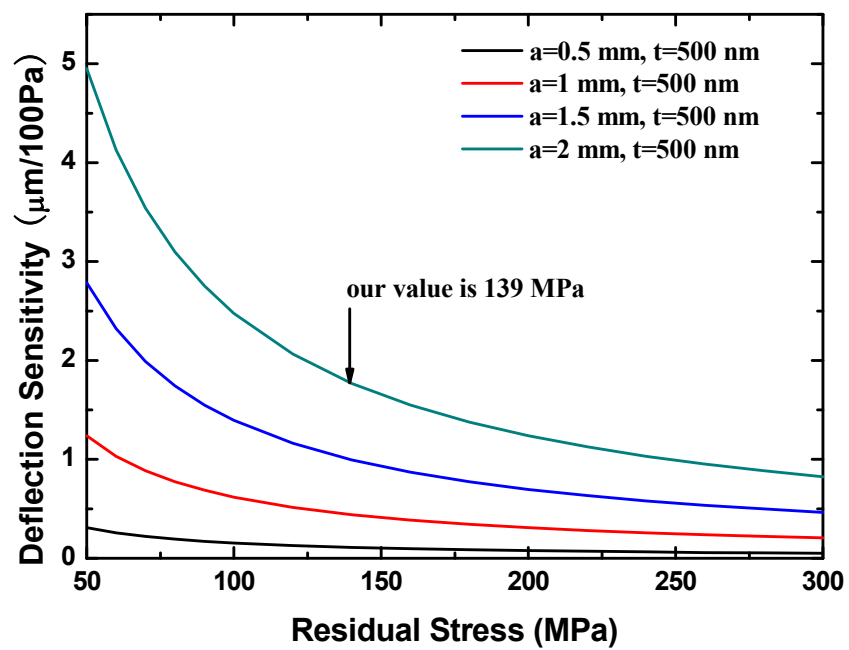

Fig. 2. The computed membrane sensitivity as function of residual stress for different film dimensions .

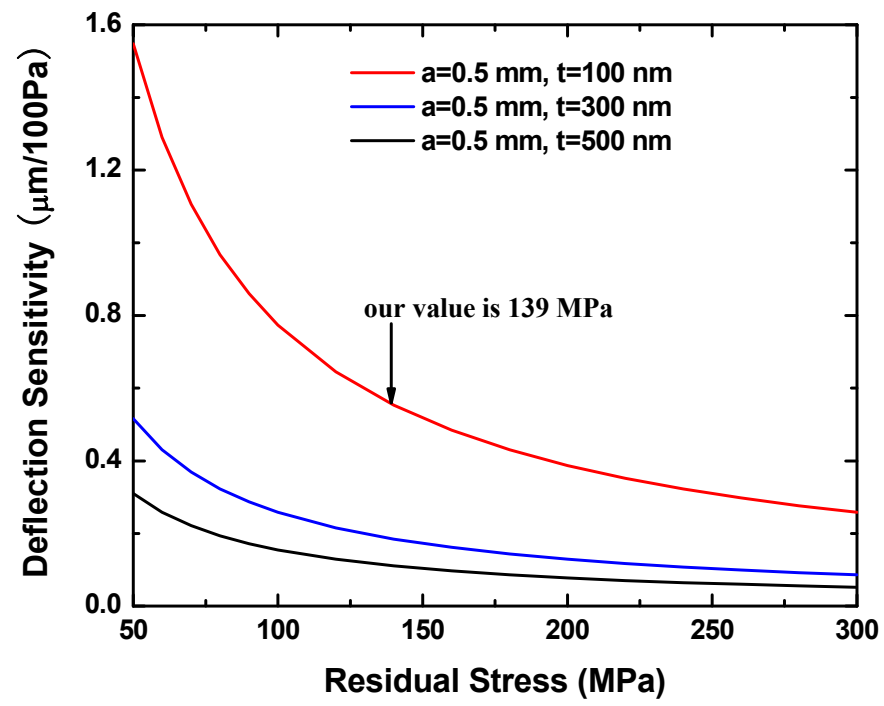

Fig. 3. The computed membrane sensitivity as function of residual stress for different film thickness 


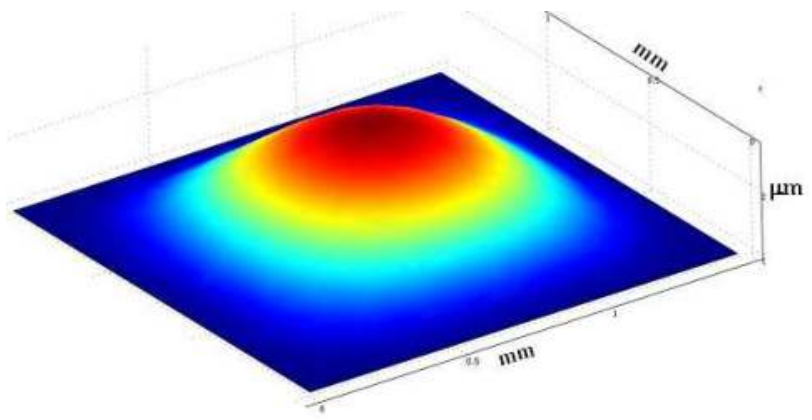

(a)

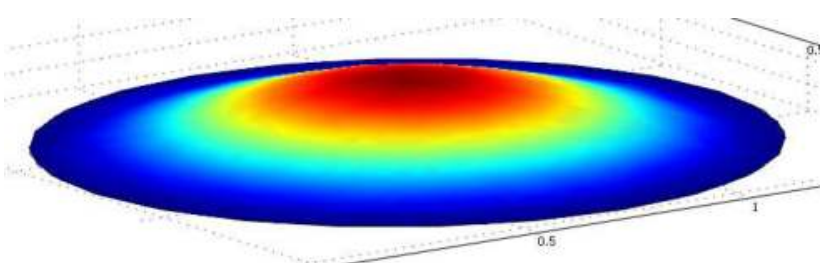

(b)

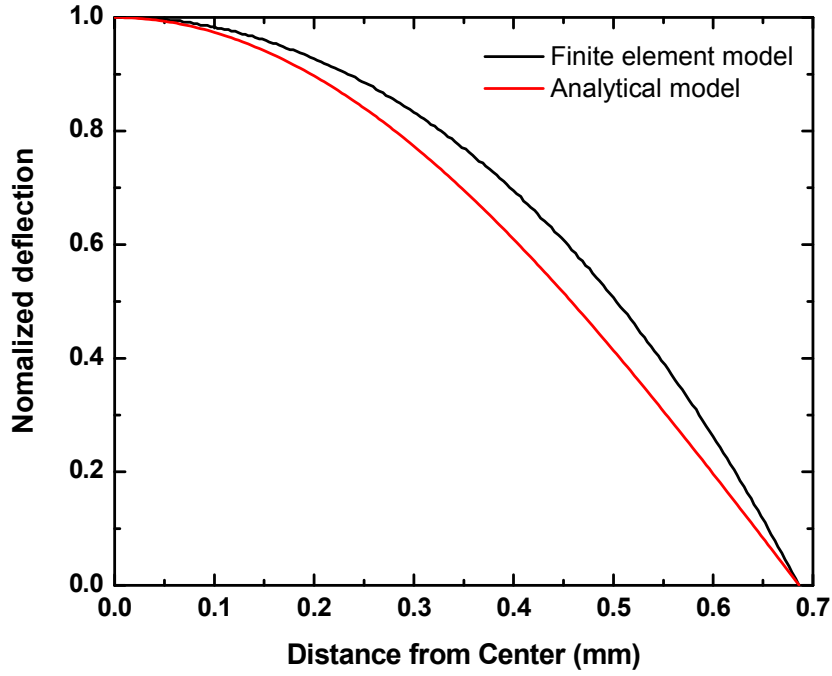

(c)

Fig. 4. The simulation of deflection of square membrane (a) and circular membrane (b) as a function of distance under pressure for the parameters listed in Table 1. (c) is the comparison for square membrane.

Because of the importance of the residual stress, a fabrication process has been designed to produce a suitable membrane. Since author plan to make a capacitive sensor at a later stage, the membrane consisted of a metallic layer in addition to the insulating amorphous SiN. 
The final membrane was designed as a tri-layer, mostly a 500nm thick a-SiN layer with a thin 10nm layer of $\mathrm{Cr}$ to improve adhesion of a thin $40 \mathrm{~nm}$ layer of Ni. The finite element method (FEM) and theory results are shown in Figure 4. In Fig.4 (a), (b) the deep red color indicates the bigger deflection.

For square membrane, the capacitance can be computed out by integral Equation 7 .

$$
\begin{aligned}
& C=\int \frac{\varepsilon_{0}}{d} d S=\varepsilon_{0} \int_{0}^{a} d x \int_{0}^{a} \frac{1}{g a p-z} d y \\
& =\varepsilon_{0} \int_{0}^{a} d x \int_{0}^{a} \frac{1}{g a p-\delta \cos \left(\frac{\pi x}{2 a}\right) \cos \left(\frac{\pi y}{2 a}\right)} d y
\end{aligned}
$$

where $\varepsilon_{0}$ is the dielectric constant, $\mathrm{d}$ is the distance of two plates, a is half width of membrane, gap is the distance between to plates as $\mathrm{P}=0, \mathrm{x}$ and $\mathrm{y}$ are the distance from the membrane center.

\subsection{Pressure sensor design}

It is shown in Figure 5 that structure of design of wireless pressure sensor. The sensor has two parts, capacitor and inductor coil. The SiNx film is 500nm thick LPCVD low stress film deposited on the silicon wafer substrate. The gap between capacitor plates is $500 \mathrm{~nm}$. The inductor coil and capacitor top plate are covered by plasma enhanced chemical vapor deposition (PECVD) silicon nitride.

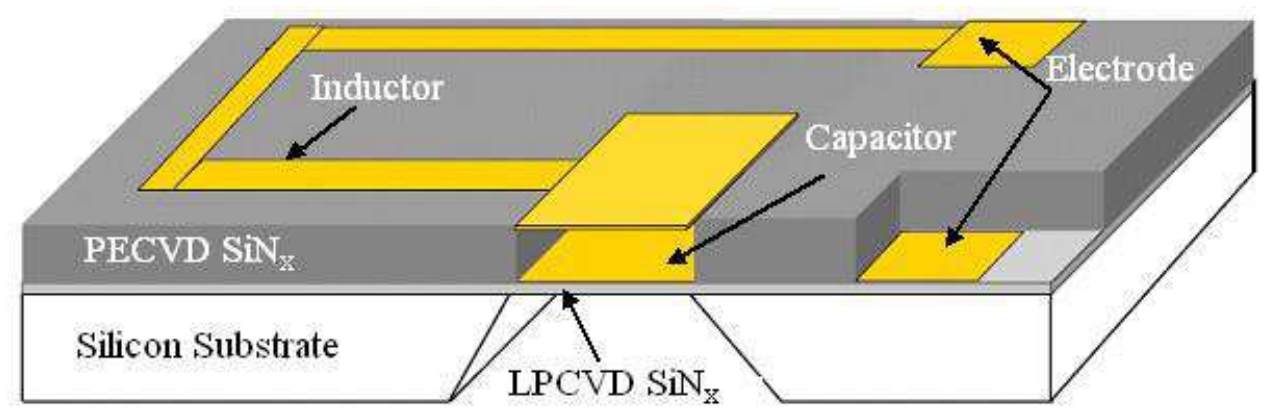

Fig. 5. The 3D structure view inter-electronic part of wireless pressure sensor.

The cross view is shown in Figure 6a. The bottom plate of capacitor can deflect under pressure change. 3D structure view inter-electronic part of wireless pressure sensor

The electrode pads, capacitor plates and inductance coil are $10 \mathrm{~nm} \mathrm{Cr}$ with $40 \mathrm{~nm} \mathrm{Ni}$. The electrical equivalent circuit of the sensor is showed in Figure 6b. External inductor or capacitor can connect to the sensor to decrease the resonant frequency. That is the reason two electrodes are opened for connection. The sensor characteristics and expected performance parameters are summarized in Table 1. 


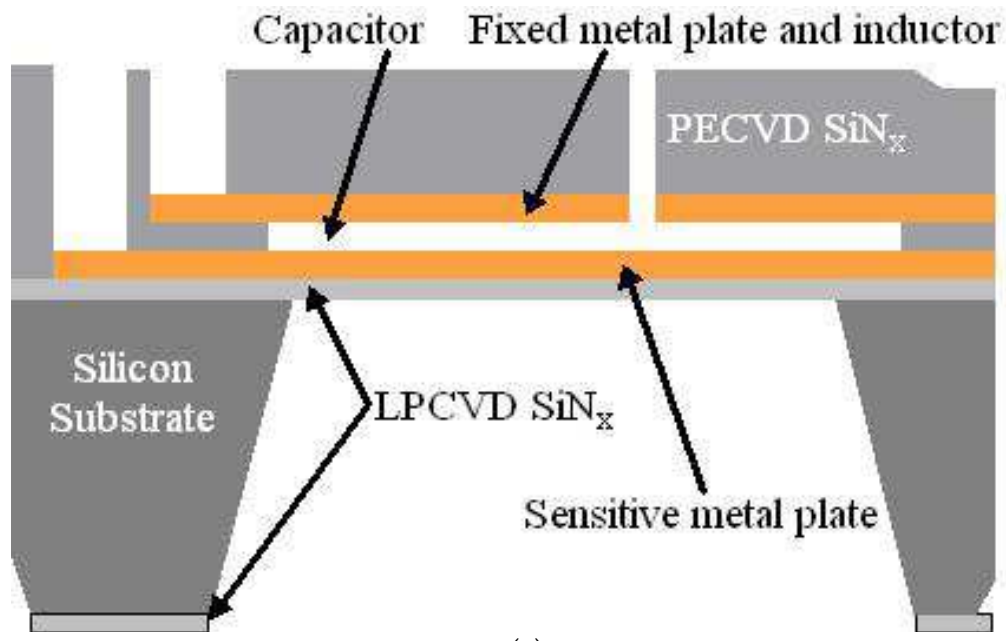

(a)

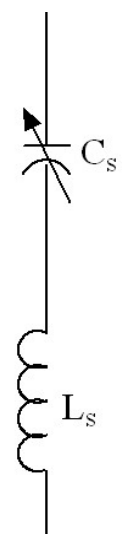

(b)

Fig. 6. (a) The cross-section of pressure sensor; (b) equivalent electrical circuit.

The self inductance of the inductor can be computed using Equation 8 (Ong, 2001).

$$
L_{S}=1.39 \times 10^{-6}(O D+I D) N^{5 / 3} \log _{10}\left(\frac{4 O D+I D}{O D-I D}\right)
$$

where ID and OD are the inner and outer diameters of the inductor, $\mathrm{N}$ is the number of turns.

Therefore, the resonant frequency of the sensor can be calculated out by.

$$
f_{0}=\frac{1}{2 \pi \sqrt{L_{s} C}}
$$




\subsection{Fabrication process}

The fabrication process of RF wireless pressure sensor is presented in Figure 7. 500nm LPCVD low stress silicon nitride is deposited on both sides of Si wafer (Figure 7a). Cr and 40
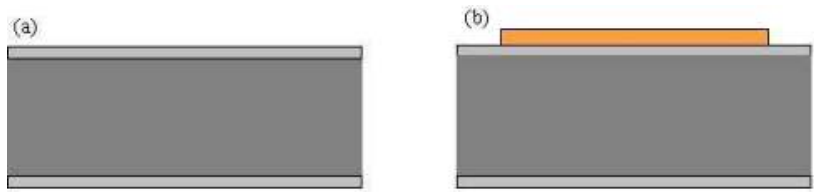

(c)
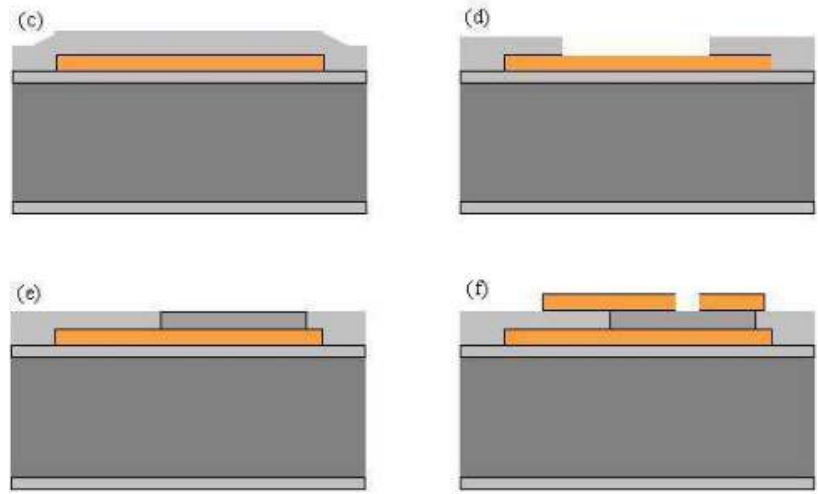

(g)
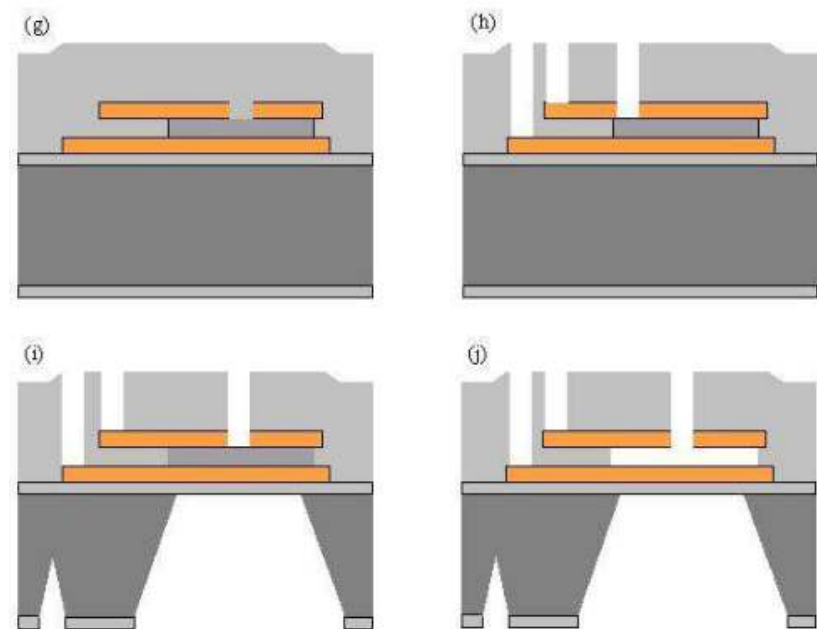

Fig. 7. Fabrication process for the wireless pressure sensor. (a) Silicon with LPCVD silicon nitride; (b) First layer metal deposition; (c) PECVD silicon nitride deposition; (d) RIE PECVD silicon Nitride; (e) silicon dioxide deposition; (f) Second layer metal deposition; (g) PECVD silicon nitride deposition; (h) RIE PECVD silicon Nitride; (i) RIE LPCVD silicon nitride and $\mathrm{KOH}$ silicon etching; (j) HF silicon dioxide etching. 
$\mathrm{nm} \mathrm{Ni}$ are deposited on a silicon wafer with $500 \mathrm{~nm}$ LPCVD low stress silicon nitride thin film (Figure 7b). PECVD silicon nitride is deposited on the metal for $750 \mathrm{~nm}$ as bottom plate of capacitor and electrode (Figure 7c). One window is opened by RIE and $500 \mathrm{~nm} \mathrm{SiO} 2$ is deposited into the window (Figure $4 \mathrm{~d}$ and Figure $7 \mathrm{e}$ ). A thin metal film $(50 \mathrm{~nm})$ is then given as top plate of capacitor, inductor and electrode (Figure 7f). A PECVD silicon nitride protection layer ( $1 \mathrm{um}$ ) is then grown on the second metal layer (Figure $7 \mathrm{~g}$ ). Then reactive ion etching (RIE) method is used to etch the PECVD silicon nitride to open window for later etching silicon dioxide (Figure $7 \mathrm{~h}$ ). The back side window of silicon nitride film is etched and the silicon wafer is selectively etched with $\mathrm{KOH}$ and the etching stops on top LPCVD silicon nitride layer (Figure 7i). The final step is etching silicon dioxide with HF to open cavity for capacitor (Figure 7j).

\section{Experimental results and discussion}

The residual stress of LPCVD silicon nitride film has been measured by using Mickleson interferometer. It is $\sigma_{0}=139 \mathrm{MPa}$. The experiment setup is showed in Figure 8.

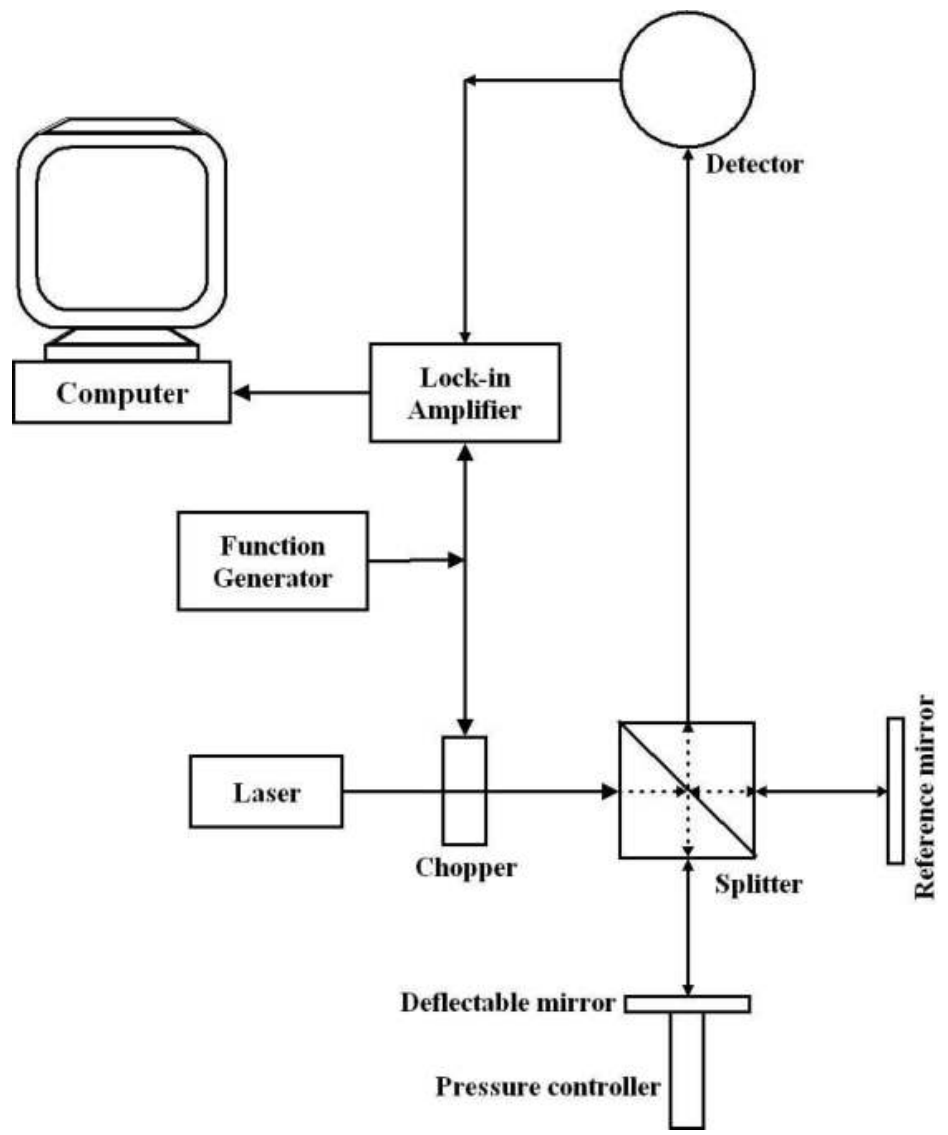

Fig. 8. Schematic of setup of optical measurement for membrane deflection and residual stress. 
Based on the design, the RF wireless flow and pressure sensor has been fabricated shown in Figure 9. In Figure 9, it shows top view of the sensor and Figure 9b shows the back side window. Because of HF etching window, the real top metal area is reduced $5 \%$. The resonant frequency as function of pressure is measured by setup shown in Figure 10. In Figure 10, manometer_1 is for pressure reading. Flow rate can be read out by the pressure difference of manometer_1 and manometer_2. The resonant frequency change in response to pressure is shown in Figure 11. The frequency shifted from $1016 \mathrm{MHz}$ to $1002 \mathrm{MHz}$. The result is replotted in Figure 12.

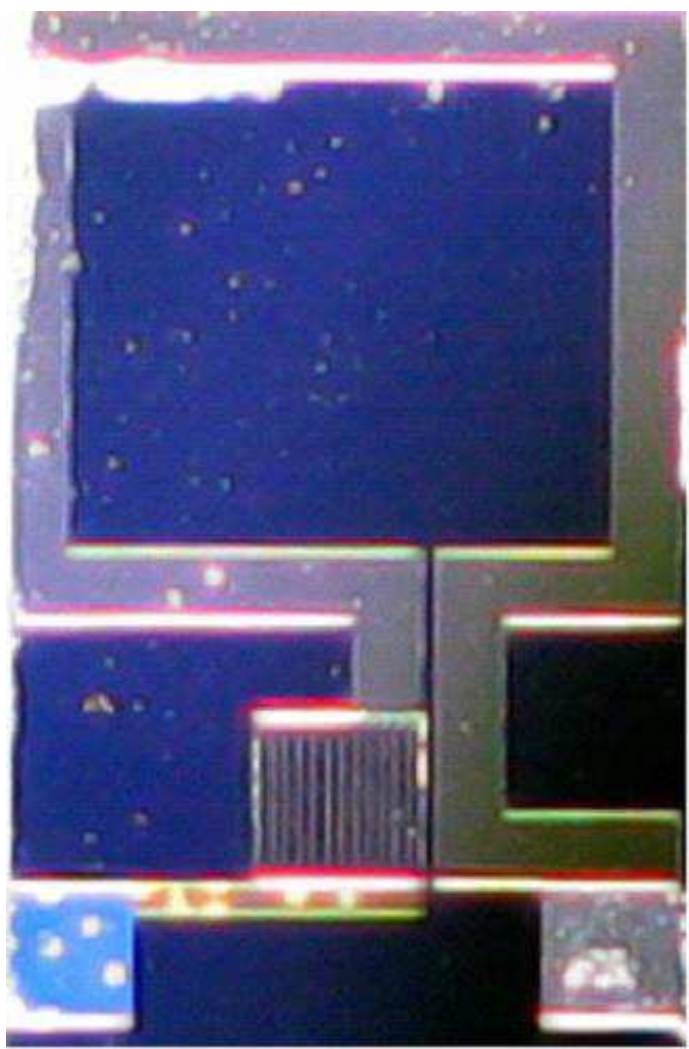

$2 \mathrm{~mm}$

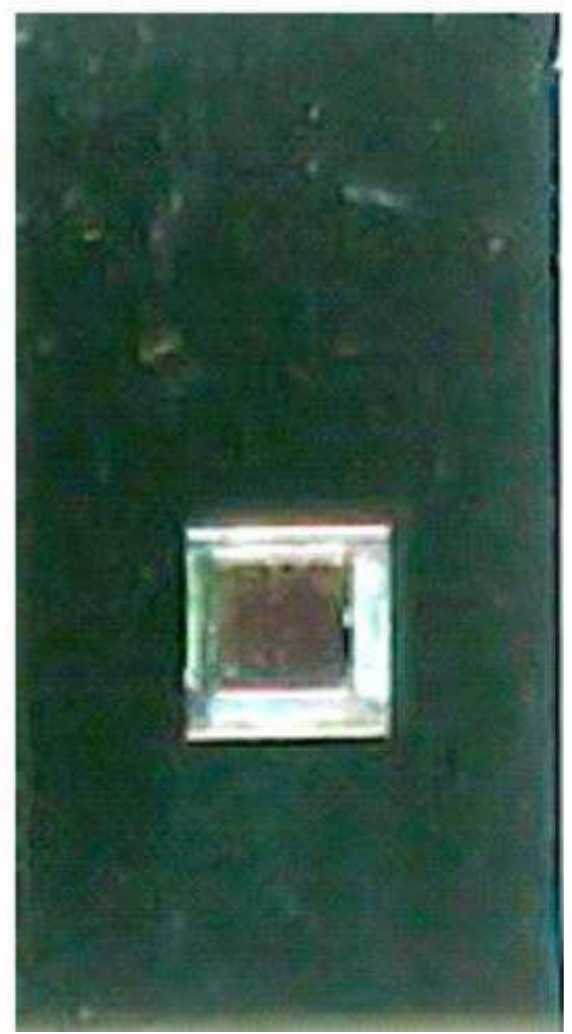

(b)

Fig. 9. The photograph of a fabricated sensor. (a) the top view of the sensor; (b) the back side view of the sensor and window. 


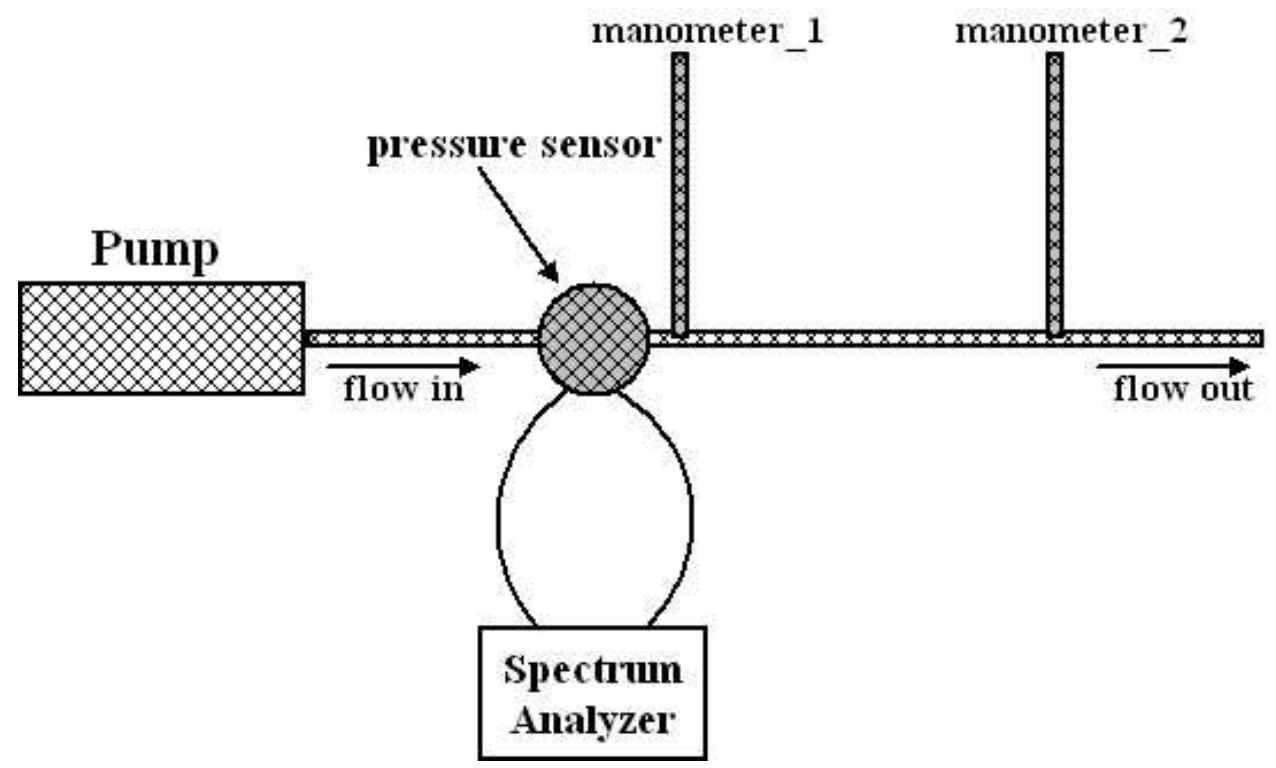

Fig. 10. Schematic of setup of wireless pressure and flow measurement.

There are several parameters can affect the sensor frequency sensitivity. Equation 10 shows the capacitance pressure sensitivity.

$$
\begin{aligned}
& \frac{d C}{d P}=\varepsilon_{0} \int_{0}^{a} d x \int_{0}^{a} \frac{z}{P \times(g a p-z)^{2}} d y \\
& =\varepsilon_{0} \int_{0}^{a} d x \int_{0}^{a} \frac{\delta \cos \left(\frac{\pi x}{2 a}\right) \cos \left(\frac{\pi y}{2 a}\right)}{P \times\left(g a p-\delta \cos \left(\frac{\pi x}{2 a}\right) \cos \left(\frac{\pi y}{2 a}\right)\right)^{2}} d y
\end{aligned}
$$

Equation 11 presents the frequency pressure sensitivity. Substituted the Equation 10 into Equation 11, the frequency pressure sensitivity can be computed out from Equation (12).

$$
\text { FreqSens }=\frac{d f_{0}}{d P}=\frac{d f_{0}}{d C} \frac{d C}{d P}=\frac{1}{4 \pi \sqrt{L C^{3}}} \frac{d C}{d P}
$$




$$
\begin{aligned}
& \text { FreqSens }=\frac{1}{4 \pi \sqrt{L C^{3}}} \varepsilon_{0} \int_{0}^{a} d x \int_{0}^{a} \frac{z}{P \times(\text { gap }-z)^{2}} d y \\
& =\frac{\varepsilon_{0}}{4 \pi \sqrt{L C^{3}}} \int_{0}^{a} d x \int_{0}^{a} \frac{\delta \cos \left(\frac{\pi x}{2 a}\right) \cos \left(\frac{\pi y}{2 a}\right)}{P \times\left(g a p-\delta \cos \left(\frac{\pi x}{2 a}\right) \cos \left(\frac{\pi y}{2 a}\right)\right)^{2}} d y
\end{aligned}
$$

The frequency pressure sensitivity was plotted as function of gap between two metal plates, residual stress, sensing membrane thickness and half width of sensing membrane shown in Figure 13-16. From Figure 13, author found as the gap increasing, the frequency pressure sensitivity decreased. Figure 14, the frequency pressure sensitivity decreased when membrane residual stress increased. In Figure 15, the frequency pressure sensitivity decreased when membrane thickness increased. From Figure 16 when the half width of membrane increased, the frequency pressure sensitivity increased.

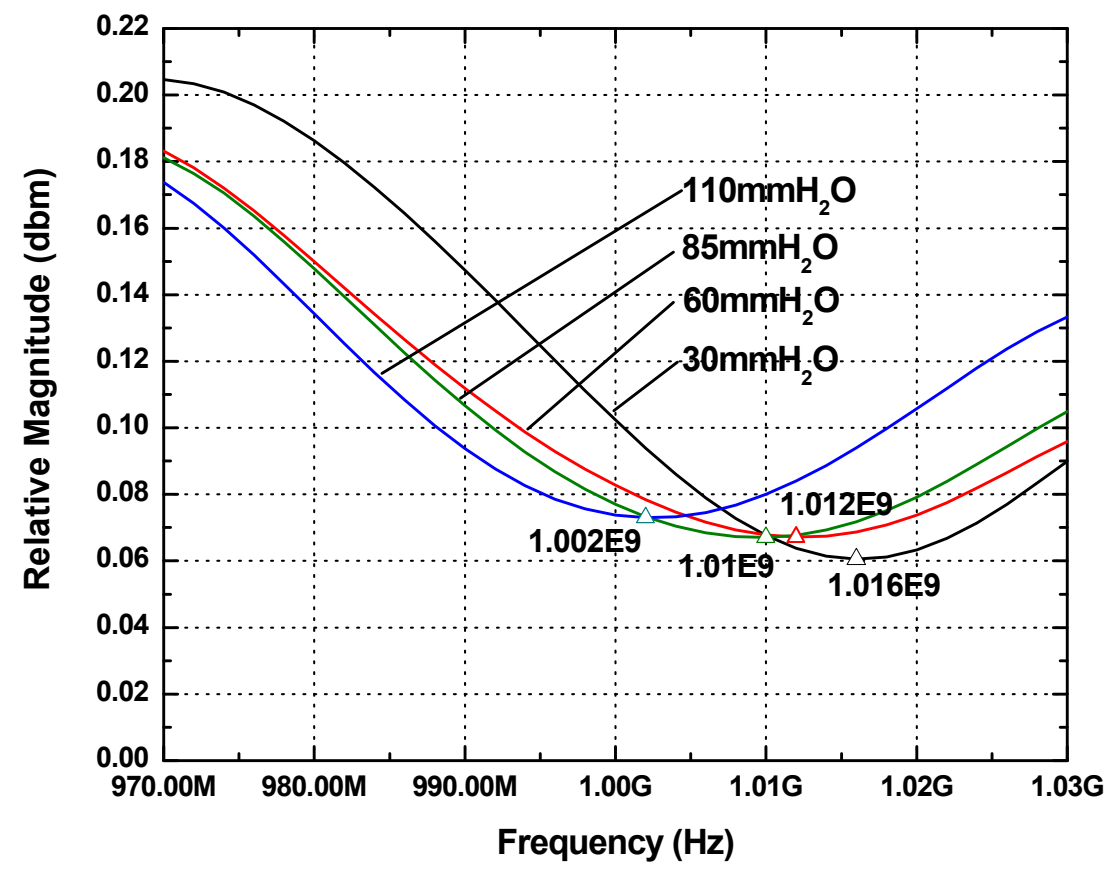

Fig. 11. The absorption response as a function of pressure. 


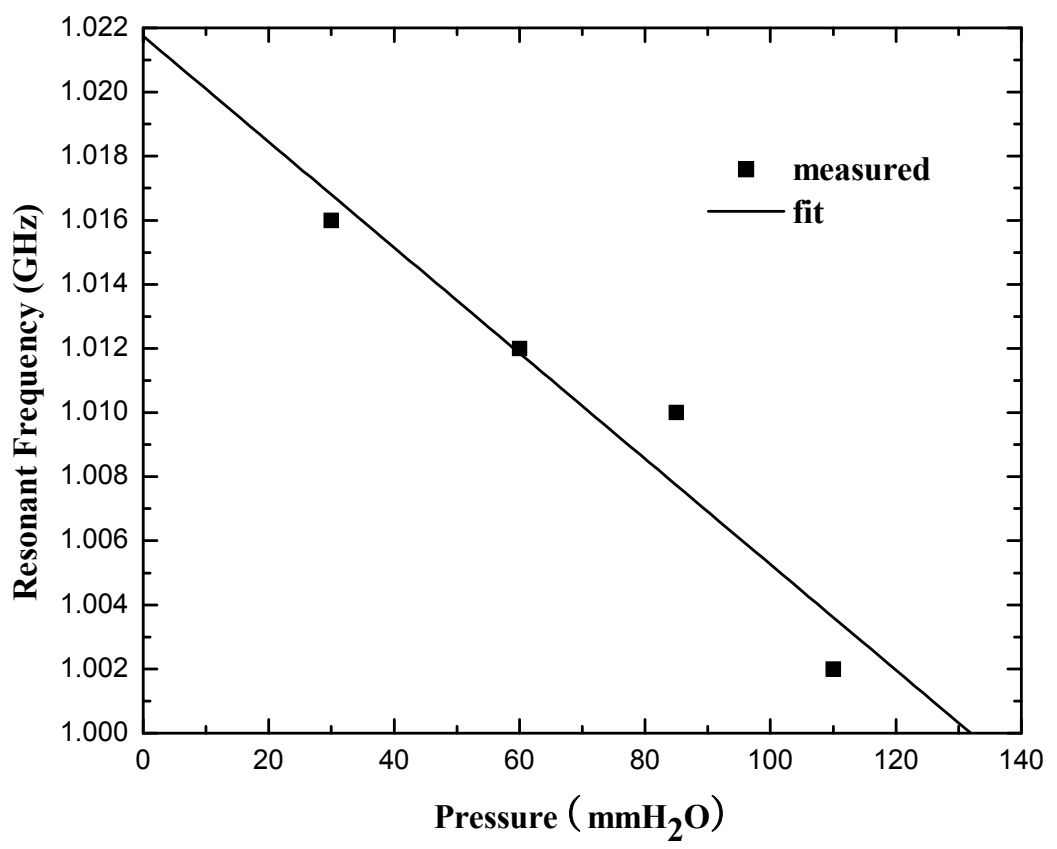

Fig. 12. The measured resonant frequency as a function of applied pressure.

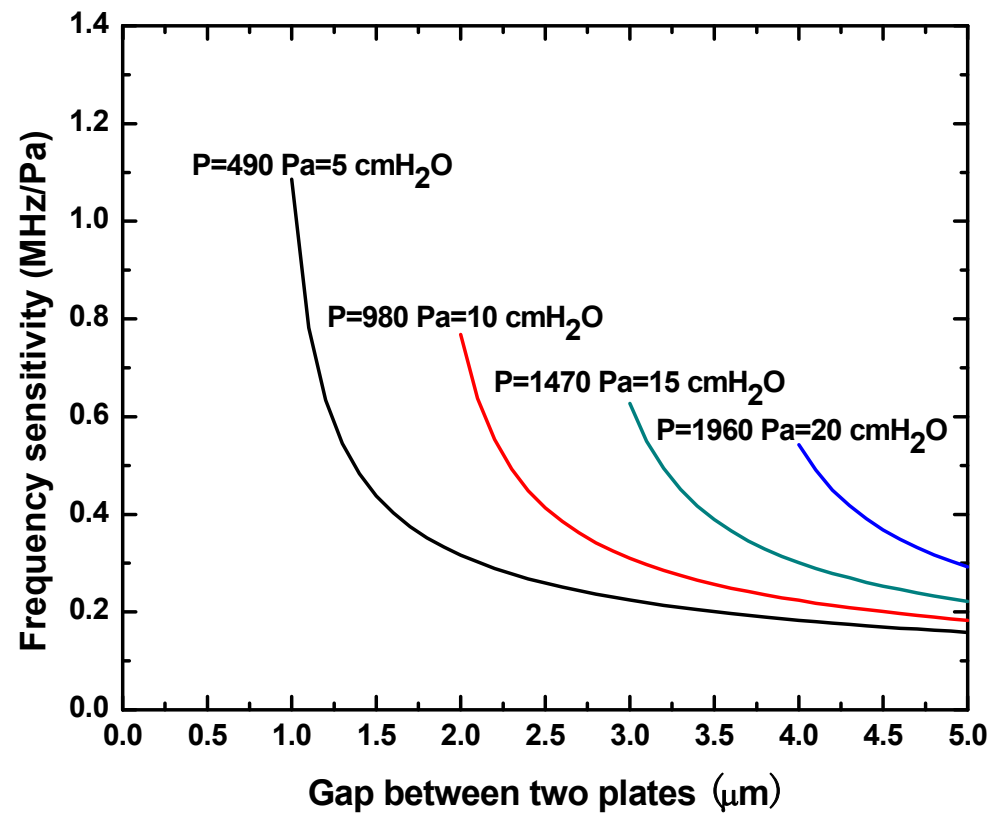

Fig. 13. The frequency pressure sensitivity responses with the gap between two metal plates 


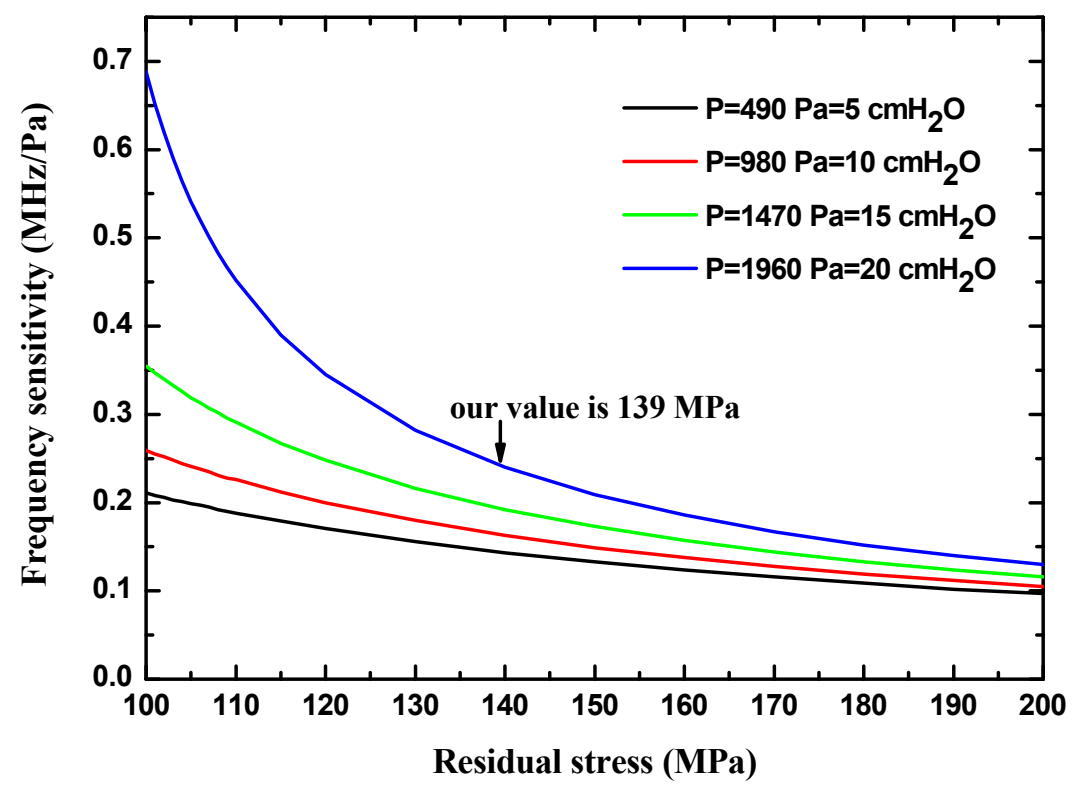

Fig. 14. The frequency pressure sensitivity responses with the residual stress of sensing membrane.

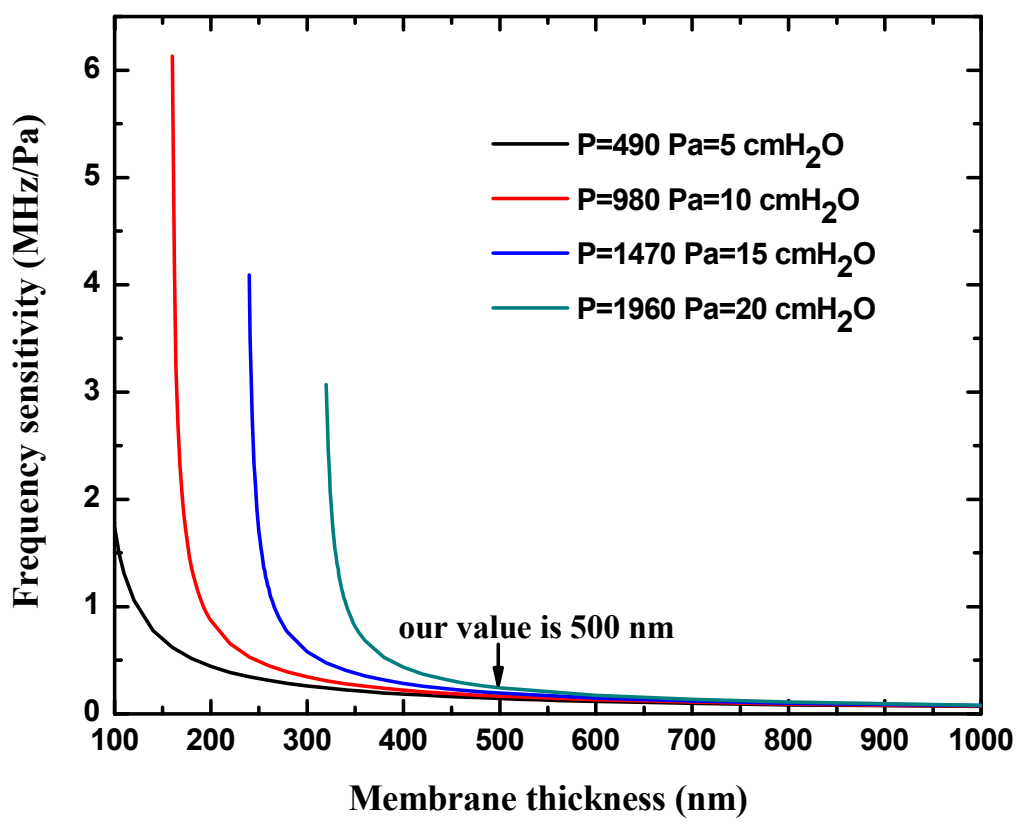

Fig. 15. The frequency pressure sensitivity responses with sensing membrane thickness. 


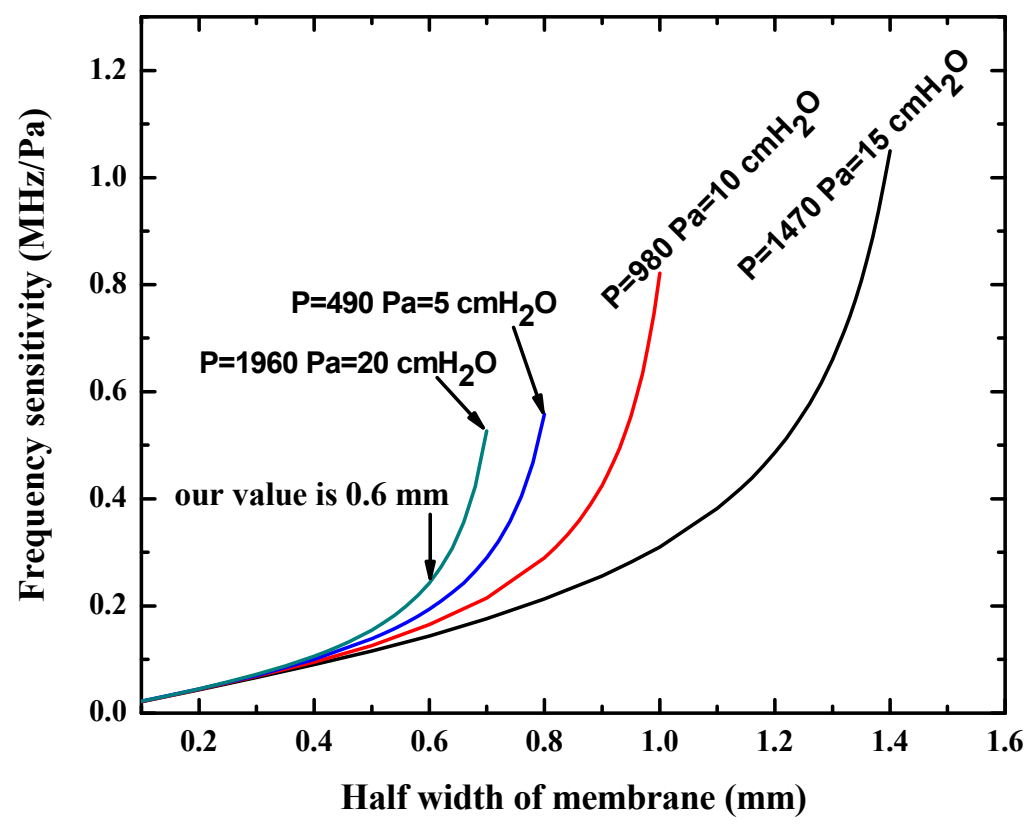

Fig. 16. The frequency pressure sensitivity responses with half width of sensing membrane.

\section{Conclusion}

A RF wireless flow and pressure sensor has been designed and fabricated. The sensor has a pressure sensitive capacitor and an inductor. The device size is $10 \mathrm{~mm} \times 4 \mathrm{~mm} \times 0.5 \mathrm{um}$ and can measure a pressure range of $0-20 \mathrm{cmH}_{2} \mathrm{O}$. The resonant frequency of the sensor has been measured and computed and the sensitivity is $1.65 \mathrm{MHz} / \mathrm{cmH}_{2} \mathrm{O}$. The parameters of sensor which can affect the frequency pressure sensitivity have been discussed. The computed results give the very useful information for sensor design. Future work will focus on optimization the distance of between two plates, improvement pressure sensitivity, development of external detection system and design of new inductor coil.

\section{Acknowledgment}

We appreciate the fabrication support by Cornell Nanofabrication Facility.

\section{References}

Puers, R; (1993). Capacitive sensors: When and how to use them, Sensors and Actuators A: Physical Vol. 37-38, pp. 93-105.

Baxter, L. K. (1997) Capacitive Sensors: Design and Applications, IEEE Press.

Akar, O.; Akin, T.; Najafi, K. (2001). A wireless batch sealed absolute capacitive pressure sensor, Sensors and Actuators A: Physical Vol. 95, pp. 29-38. 
Ong, K. G.; Grimes, C. A.; Robbins , C. L.; Singh, R. S. (2001). Design and application of a wireless, passive, resonant-circuit environmental monitoring sensor, Sensors and Actuators A: Physical Vol.93, pp. 33-43.

Grimes, C. A.; Kouzoudis, D. (2000). Remote query measurement of pressure, fluid-flow velocity, and humidity using magnetoelastic thick-film sensors, Sensors and Actuators A: Physical Vol.84, pp. 205-212.

Oosterbroek, R. E.; Lammerink, T. S. J.; Berenschot, J. W.; Krijnen, G. J. M.; Elwenspoek, M. C.; Berg, A. van den. (1999). A micromachined pressure/flow-sensor, Sensors and Actuators A: Physical Vol.77, pp.167-177.

Vlassak, J.J.; Nix, W.D. (1992). A new bulge test technique for the determination of Young's modulus and Poisson's ratio of thin films, Journal of material research, Vol.7, pp. 3242-3249.

Pan, J. Y.; Lin, P.; Maseeh, F.; Senturia, S. D. (1990). Verification of FEM analysis of loaddeflection methods for measuring mechanical properties of thin films, solid-State Sensor and Actuator Workshop, 4th Technical Digest., IEEE, pp. 70-73. 


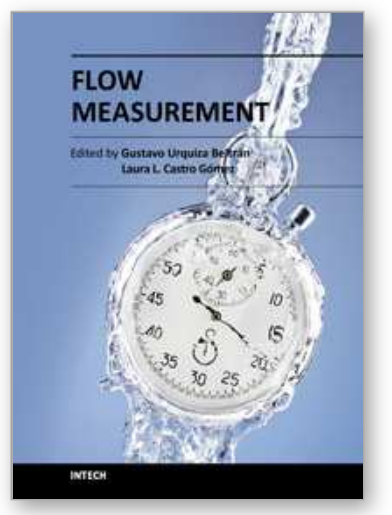

\author{
Flow Measurement \\ Edited by Dr. Gustavo Urquiza
}

ISBN 978-953-51-0390-5

Hard cover, 184 pages

Publisher InTech

Published online 28, March, 2012

Published in print edition March, 2012

The Flow Measurement book comprises different topics. The book is divided in four sections. The first section deals with the basic theories and application in microflows, including all the difficulties that such phenomenon implies. The second section includes topics related to the measurement of biphasic flows, such as separation of different phases to perform its individual measurement and other experimental methods. The third section deals with the development of various experiments and devices for gas flow, principally air and combustible gases. The last section presents 2 chapters on the theory and methods to perform flow measurements indirectly by means on pressure changes, applied on large and small flows.

\title{
How to reference
}

In order to correctly reference this scholarly work, feel free to copy and paste the following:

Sheng Liu, Reginald Farrow and Gordon Thomas (2012). Microfabricated Implantable Pressure Sensor for Flow Measurement, Flow Measurement, Dr. Gustavo Urquiza (Ed.), ISBN: 978-953-51-0390-5, InTech, Available from: http://www.intechopen.com/books/flow-measurement/microfabricated-implantable-pressuresensor-for-flow-measurement

\section{INTECH}

open science | open minds

\section{InTech Europe}

University Campus STeP Ri Slavka Krautzeka 83/A 51000 Rijeka, Croatia Phone: +385 (51) 770447

Fax: +385 (51) 686166 www.intechopen.com

\section{InTech China}

Unit 405, Office Block, Hotel Equatorial Shanghai No.65, Yan An Road (West), Shanghai, 200040, China 中国上海市延安西路65号上海国际贵都大饭店办公楼 405 单元 Phone: +86-21-62489820

Fax: $+86-21-62489821$ 
(C) 2012 The Author(s). Licensee IntechOpen. This is an open access article distributed under the terms of the Creative Commons Attribution 3.0 License, which permits unrestricted use, distribution, and reproduction in any medium, provided the original work is properly cited. 